\title{
The World Health Organisation's recommendation on breastfeeding: Assessing knowledge and practice among mothers in Abuja, Northern Nigeria
}

\author{
Nneoma Macphilip-Chikwendu, ${ }^{1}$ Onyinye Hope Chime, ${ }^{2,3}$ Chigbo Macphilip Chikwendu, ${ }^{4}$ \\ Christian Osaeloka Ekwueme ${ }^{1,5}$
}

${ }^{1}$ Department of Community Medicine, University of Nigeria Teaching Hospital, Enugu; ${ }^{2}$ Department of
Community Medicine, Enugu State University Teaching Hospital, Enugu; ${ }^{3}$ Department of Community
Medicine, Enugu State University College of Medicine, Enugu; ${ }^{4}$ Health Strategy and delivery Foundation,
Abuja; ${ }^{5}$ Department of Community Medicine, University of Nigeria College of Medicine, Enugu, Nigeria

Correspondence: Onyinye Hope Chime, Department of Community Medicine, Enugu State University Teaching Hospital, Enugu, and Department of Community Medicine, Enugu State University College of Medicine, Enugu, Nigeria.

E-mail: onyinye.chime@esut.edu.ng

Tel.: +234.8066900527 .

Key words: Breast feeding; exclusive breastfeeding; knowledge; practice; Nigeria; World Health Organisation.

Acknowledgements: We thank the management and staff of the various health facilities for their assistance during the course of our work. Special thank goes to the mothers for their valuable participation in this study.

Contributions: NC conceived and designed the study. CC supervised data collection. OC analysed the data, wrote the results and the first draft of the manuscript. OE reviewed the final manuscript and supervised the work. All authors read and approved the final manuscript.

Conflicts of interest: The authors declare no conflict of interests.

Availability of data and materials: All study materials and data will be available at the University of Nigeria, Community Medicine Departmental library for a period of five years after which it may be destroyed. They are available from the authors on request with permission from the department chair.

Ethics approval and consent to participate: Ethical approval for the study was obtained from the Health Research and Ethics Committee of Federal Capital Territory with number FHREC/2019/01/54/13-05-19. Approval was also sought from the management of selected health facilities. Written informed consents were obtained from the participants with detailed accounts of the study objectives, procedures, risks and benefits.

Received for publication: 4 November 2020

Revision received: 15 January 2021.

Accepted for publication: 22 February 2021.

This work is licensed under a Creative Commons Attribution NonCommercial 4.0 License (CC BY-NC 4.0).

${ }^{(C)}$ Copyright: the Author(s), 2021

Licensee PAGEPress, Italy

Annals of Clinical and Biomedical Research 2021; 2:119

doi:10.4081/acbr.2021.119

\begin{abstract}
Despite the fact that breastfeeding remains the healthiest, simplest and least expensive means of meeting the nutritional needs of newborns and infants, the knowledge and practice as recommended by WHO remain low in most low-and middle-income countries. This study aims at exploring the gap in the knowledge of exclusive breastfeeding among mothers in Northern Nigeria as well as comparing their practises with the WHO recommendations. This was a cross-sectional facility-based study among 343 mothers in Abuja, Northern Nigeria. Data was collected over 8 weeks using a structured interviewer-administered questionnaire assessing knowledge and practise of breastfeeding based on the WHO recommendations. Data collected were analyzed using SPSS version 22. Chi square test of statistical significance was used to measure the degree of bivariate associations at a level of $p<0.05$. Only $42.6 \%$ of the mothers had good general knowledge of breastfeeding. Exclusive breastfeeding for 6 months was practised by 232 (75.1\%) mothers. Having more than one child was associated with good knowledge of breastfeeding $\left(\chi^{2}=7.331, \mathrm{p}=0.007\right)$ while having poor knowledge of breastfeeding $\left(\chi^{2}=5.722, \mathrm{p}=0.017\right)$ was associated with exclusive breastfeeding practise. Commonest reasons for not practising exclusive breastfeeding were insufficient breast milk (38.7\%) and resumption of work (19.8\%). In this study, the practise of initiating breastfeeding within an hour after birth and exclusive breastfeeding are both in line with WHO recommendations. Continuous breastfeeding awareness campaigns are needed to improve knowledge and sustain the practise of exclusive breastfeeding.
\end{abstract}

\section{Introduction}

Breastfeeding is the healthiest, simplest and least expensive means of meeting the nutritional needs of newborns and infants. ${ }^{1}$ Breast milk is known to contain all essential nutrients; carbohydrates, essential fats, proteins, minerals, and immunological factors required for the optimal growth and development of infants in the required quantity; hence, it is the ideal meal for babies. ${ }^{2}$ Globally, this practice is accepted by all cultures as the mainstay feeding for the newborn although cow milk can double as a substitute. Around the world, at least $95 \%$ of babies are breastfed at some point in their lives though this rate varies widely between countries. ${ }^{3}$ In low and middle-income countries, 1 in 25 babies are never breastfed while $21 \%$ of babies in high-income countries 
never receive breast milk. ${ }^{3}$ Given the importance of breastfeeding, the World Health Organisation (WHO) adopted the "Innocenti Declaration" which emphasizes the need to initiate breastfeeding within the first hour of delivery. ${ }^{4}$ This practise ensures that the infant receives colostrum which is rich in immunoglobulins and other bioactive molecules, including growth factors that are important for nutrition, growth, development of newborn infants and for building passive immunity. United Nations Children's Fund's (UNICEF) and WHO's global recommendations for optimal infant feeding as set out in the Global Strategy are, "exclusive breastfeeding (EBF) for 6 months, complementary feeding starting from the age of 6 months with continued breastfeeding for at least 2 years of age or beyond." 5 This is also adopted by the National policy on infant and young child feeding in Nigeria. ${ }^{6} \mathrm{EBF}$ is a type of breastfeeding practise involving feeding on breast milk or expressed breast milk only, excluding water, breast milk substitutes, other liquids and solid foods, in the first 6 months of life. ${ }^{3}$ The first two years of life provide a critical window of opportunity for ensuring children's appropriate growth and development through optimal feeding hence the recommendation that breastfeeding should continue for at least two years post-delivery. ${ }^{4}$

The advancement, fortification, and care of breastfeeding are exceptional economic strategies for improving child-wellbeing and decreasing the burden of childhood disease, particularly in developing countries. ${ }^{7}$ Despite the benefits of breastfeeding, the rate of EBF remains low in most low-and middle-income countries resulting in over 1 million child mortalities and morbidities annually. ${ }^{2,8}$ In most developing countries, only $39 \%$ of children aged less than 6 months are exclusively breastfed, and just about 58\% of children 20-23 months old benefit from the practise of continued breast feeding, which highlights the poor overall breastfeeding practices in the world. ${ }^{9}$ In sub-Saharan countries, while almost all children born in Nigeria are breastfed, the rate of EBF is low and declining - from $28 \%$ in 1999 to $27 \%$ in 2018 compared to $52.0 \%$ in Ghana and $58.0 \%$ in Togo. ${ }^{10,11}$

In Nigeria, changes in infant feeding practises have occurred over time due to factors such as alien cultures, values, education and urbanization with consequent changes in lifestyle. ${ }^{12}$ Many policies and programs have been designed and implemented in Nigeria to address these factors. A lot of behavioural change communication interventions have focused on improving awareness, knowledge and information on breastfeeding practices. However, evidence from a study had posited that knowledge of EBF does not correlate with its practise; the fact that $65 \%$ of the respondents were informed of EBF did not guarantee their practicing it. ${ }^{13}$

In the Federal Capital Territory (FCT), Abuja, evidence also suggests that despite the health education provided at hospitals and communities on awareness of EBF up to six months, mothers are reluctant to stick to the teachings, making rates of adherence low. ${ }^{13}$ Child nutrition programs worldwide consistently require investments and commitments to improve infant feeding practises in order to have maximum impact on children's lives. ${ }^{8}$ This study therefore attempts to explore the gap in the knowledge and practises of breastfeeding among mothers and compare the practises with WHO's recommended breastfeeding practises.

\section{Materials and Methods}

\section{Study area}

The study area is Abuja Municipal Area Council (AMAC) in the FCT. Until a few decades ago, AMAC was predominantly inhabited by the Gbagyi people, however rapid urbanization spurred by the relocation of the seat of the government of the Federal Republic of Nigeria from Lagos to the council area in 1991 has turned it into a cosmopolitan metropolis, hosting people of different races and colours, as well as languages and tribes. The AMAC is further divided into 5 geographical districts namely Gwarimpa, Maitama, Wuse II, Wuse Zones 5 and 6, and Garki District. There are 486 hospitals in AMAC consisting of primary, secondary and tertiary facilities that are either private or public owned. ${ }^{14}$

\section{Study design, population and sampling}

The study was a cross-sectional facility-based study and assessed the knowledge and practice of breastfeeding among

Table 1. Socio-demographic characteristics of breastfeeding mothers in Abuja.

$\begin{array}{ccc}\text { Variables } & \text { Frequency } & \text { Percentage } \\ \mathrm{N}=343 & (\%)\end{array}$

Age

Mean \pm STD

$31.32 \pm 4.61$

\begin{tabular}{ccc} 
Age Categorized & & \\
$19-28$ years & 88 & 25.7 \\
$29-38$ years & 234 & 68.2 \\
$39-48$ years & 19 & 5.5 \\
$\geq 49$ years & 2 & 0.6 \\
\hline
\end{tabular}

Marital status

$\begin{array}{lll}\text { Single } & 5 & 1.5\end{array}$

Married $\quad 329$

$\begin{array}{lll}\text { Separated } & 3 & 0.9\end{array}$

Widowed $\quad 5 \quad 1.5$

Divorced $\quad 1 \quad 0.3$

\begin{tabular}{lcc} 
Religion & & \\
Christian & 285 & 83.0 \\
Islam & 53 & 15.5 \\
Others & 5 & 1.5 \\
\hline
\end{tabular}

Tribe

$\begin{array}{lll}\text { Igbo } & 135 & 39.4\end{array}$

Yoruba $\quad 51 \quad 14.9$

Hausa $\quad 44 \quad 12.8$

$\begin{array}{lll}\text { Others } \quad 113 & 32.9\end{array}$

Educational Qualification
Informal education

$\begin{array}{lll}\text { Primary } & 19 & 5.5\end{array}$

Secondary $\quad 15 \quad 4.4$

$\begin{array}{lll}\text { Tertiary } & 305 & 88.9\end{array}$

Qur'anic 3

Employment status

Student 14

Unemployed $\quad 51 \quad 14.9$

Informally/Self-employed $\quad 106 \quad 30.9$

Formally employed $\quad 172 \quad 50.1$

$\begin{gathered}\text { Number of Children } \\ \text { Mean } \pm \text { STD }\end{gathered}$
$1.59 \pm 0.61$

\begin{tabular}{ccc}
\hline $\begin{array}{c}\text { Number of Children Categorized } \\
1\end{array}$ & 163 & \\
$<4$ & 159 & 47.5 \\
$>4$ & 21 & 46.4 \\
Age of last Child & 6.1 \\
$<6$ months & 143 & \\
6 - 12 months & 83 & 41.7 \\
$1-2$ years & 66 & 24.2 \\
$2-5$ years & 51 & 19.2 \\
\hline
\end{tabular}


mothers of infants, above 18 years of age assessing maternal and child healthcare services in secondary health facilities within AMAC using quantitative study instruments for a period of 8 weeks from April to June, 2019.

Gwarimpa district was selected for the study. The secondary health facilities within this district were further stratified into public and private owned, and from each stratum, 2 public (Federal Medical Centre, Jabi and Federal Medical Centre, Gwarimpa) and 2 private facilities (Nisa Premier Hospital, and Arewa Specialist Hospital) were selected. Fisher's statistical formula using a prevalence of $65 \%$ from a previous study was used to determine the minimum sample size of 400 for the study. ${ }^{13}$ The sum of the average two-monthly attendance rates for ante-natal, post-natal and immunization clinics in the 4 facilities was calculated to get the sampling frame. The sample size was proportionately allocated to the facilities according to their patient load and the study participants were selected using systematic random sampling during their clinic visits. Three hundred and forty-three (343) questionnaires were retrieved bringing the response rate to $85.75 \%$.

\section{Data collection and analysis}

The study instrument was a structured interviewer-administered questionnaire comprising of 3 sections on socio demographics, knowledge and practise of breastfeeding. Knowledge was assessed using 15 questions extracted from WHO tool for assessing national practises, policies and programmes on breastfeeding. ${ }^{15}$ Each correct answer scores one point. The practise of EBF was assessed with eight questions based on WHO recommended EBF practise. ${ }^{4}$ This measurement assessed such practices such as; initiation of breastfeeding within an hour after birth, practice of EBF and other questions to enlist responses peculiar to breastfeeding practises.

Data entry and analysis was done using Statistical Package for Social Sciences (SPSS) version 22. Descriptive statistics, frequen- cies and proportions were derived for categorical variables. Chi square test of statistical significance, student t-test and multivariate analysis using binary logistic regression analysis were used in the analysis. Level of statistical significance was set at predetermined p-value of $<0.05$.

Ethical approval for the study was obtained from the Health Research and Ethics Committee of Federal Capital Territory with number FHREC/2019/01/54/13-05-19. Approval was also sought from the management of selected health facilities. Written informed consents were obtained from the participants with detailed accounts of the study objectives, procedures, risks and benefits.

\section{Results}

Table 1 above shows the socio-demographic characteristics of respondent. The mean age of the participants in this study is 31.32 \pm 4.61 years with the highest proportion of respondents within the age group 29-38 years. Majority of the respondents were married (95.9\%), Christians (83.0\%) and had tertiary educational qualifications $(88.9 \%)$. On the employment status of the respondents, about half $(50.1 \%)$ were found to be in formal employment while others were self-employed (30.9\%), unemployed $(14.9 \%)$ or students (4.1\%). A total of 343 mothers participated in this study. The majority of them $(92.1 \%)$ knew that the best time to initiate breastfeeding is within an hour after birth. However, $25.4 \%$ did not know that exclusively breastfed children should not receive any other food apart from breast milk. Likewise, only 5 respondents reported that EBF should last for 6 months from birth. Only 144 (42.0\%) of the respondents knew that children should be breastfed for up to 2 years of age. The assessment of knowledge of breastfeeding among mothers showed that less than fifty per cent (42.6\%) of the mothers had good knowledge while majority (57.4\%) demonstrat-

Table 2. Knowledge of breastfeeding among mothers in Abuja.

\begin{tabular}{|c|c|c|}
\hline \multirow[t]{2}{*}{ Variable } & \multicolumn{2}{|c|}{$\begin{array}{c}\text { Knowledge } \\
\mathrm{N}=343\end{array}$} \\
\hline & $\begin{array}{l}\text { True } \\
\text { n (\%) }\end{array}$ & $\begin{array}{l}\text { False } \\
\text { n (\%) }\end{array}$ \\
\hline The best time for initiating breastfeeding is within an hour after birth & $316(92.1)$ & $27(7.9)$ \\
\hline Ever heard of exclusive breastfeeding & $330(96.2)$ & $13(3.8)$ \\
\hline Recommended duration for exclusive breastfeeding is 0 - 6 months & $301(87.8)$ & $42(12.2)$ \\
\hline First yellowish breast milk (colostrums) expressed by mother has high nutritional and protective value & $333(97.1)$ & $10(2.9)$ \\
\hline Breast milk contains enough water for baby's needs in the first 6 months of life & $321(93.6)$ & $22(6.4)$ \\
\hline Bottle feeding has adverse effects on baby's health & $215(62.7)$ & $128(37.3)$ \\
\hline Correct age to start weaning baby is after six months & $56(16.3)$ & $287(83.7)$ \\
\hline Exclusively breastfed children should not be given anything else & $256(74.6)$ & $87(25.4)$ \\
\hline Recommended duration to continue breast feeding is at least for 2 years & $144(42.0)$ & $199(58.0)$ \\
\hline A mother who delivered through caesarian section should start breastfeeding immediately after birth & $306(89.2)$ & $37(10.8)$ \\
\hline The immunity factors in breast milk can help the baby to fight off infections & $308(89.8)$ & $35(10.2)$ \\
\hline Breast milk contains vitamins and enzymes which aid the baby's digestion & $265(77.3)$ & $78(22.7)$ \\
\hline Breast milk is the ideal form of nutrition for infants & $299(87.2)$ & $44(12.8)$ \\
\hline Breastfeeding mothers return to their pre-pregnancy weight faster than those who do not breastfeed & $158(46.1)$ & $185(53.9)$ \\
\hline Breastfeeding reduces mothers' risk for breast and ovarian cancer & $234(68.2)$ & $109(31.8)$ \\
\hline \multicolumn{3}{|l|}{ Knowledge categorized } \\
\hline Poor & $197(57.4)$ & \\
\hline Good & $146(42.6)$ & \\
\hline
\end{tabular}

Categorized into Poor and Good knowledge using average score of 12 out of 15 points. 
ed poor knowledge (Table 2).

Table 3 shows the breastfeeding practises of nursing mothers. Out of 343 respondents who participated in this study, 309 (90.1\%) breastfed their babies with 259 (75.5\%) initiating breastfeeding immediately after birth. According to WHO recommendation, EBF till six months was practised by $232(75.1 \%)$ mothers. Only 6 $(1.7 \%)$ of the respondents' breastfed their babies for up to 2 years as recommended. More than two-third of the respondents $(86.1 \%)$ breastfed their babies on demand and majority (89.2\%) would recommend EBF to other mothers.

Table 4 reveals reasons for not adhering to the recommendation of EBF. The majority of the respondents felt breast milk is insufficient for their babies 43 (38.7\%) while only one respondent $(0.9 \%)$ feels EBF is not necessary.

Table 5 outlines the factors associated with knowledge of breastfeeding. Mothers with more than a child (61.0\%) had better knowledge when compared with their counterparts with just one child $(39.0 \%)$ and the difference in proportion was found to be statistically significant $\left(\chi^{2}=7.331, \mathrm{p}=0.007\right)$. Respondents more than 30 years $(52.1 \%)$ were slightly more knowledgeable on breastfeeding than the younger mothers. This finding was however not statistically significant $\left(\chi^{2}=0.056, \mathrm{p}=0.813\right)$.

In Table 6, a significantly higher proportion of respondents with poor knowledge $(53.0 \%)$ had better EBF practise when compared with those with good knowledge $\left(\chi^{2}=5.722, p=0.017\right)$.

\section{Discussion}

From the result, majority $(87.8 \%)$ of the mothers knew that EBF should last for the first six months of life. The duration of EBF is a good index in accessing the knowledge of breastfeeding as recommended by the WHO as mothers who know the recommended duration are expected to practice it. This finding is higher than that reported by Odu et al $(64.6 \%)$ in Osun, South-west Nigeria. ${ }^{12}$ This is surprising as the study was conducted mainly in the urban area among mothers of infants attending infants Welfare Clinics where the WHO recommended baby-friendly practices are expected to be optimal. Across different countries in East Africa, findings from a systematic review revealed that only $49.2 \%$ of the mothers knew that the expected duration of EBF was for the first six months of life. ${ }^{16}$ This finding is limited as majority of the studies included in the review had small sample size, thereby restricting generalisation of the findings. Again the literacy levels and access to health information is expected to vary across various East African countries.

The overall knowledge of breastfeeding in this study is $42.6 \%$. The WHO recommended baby-friendly policy implores education of women on the practice and benefits of breastfeeding during ante-natal and post-natal health services. This Baby Friendly Hospital Initiative (BFHI) was introduced in Nigeria in 1992 and Onah et al. in his study, revealed that contact with BFHI designated hospitals increase both WHO recommended knowledge and practise. ${ }^{17}$ The prevalence recorded in this study is inadequate considering the fact that the study was carried out on mothers attending maternal and child health clinics where they are expected to

Table 3. Breastfeeding practises among mothers in Abuja as recommended by WHO.

\begin{tabular}{|c|c|c|}
\hline Variables & Frequency & Percentage \\
\hline $\begin{array}{l}\text { Breastfed baby } \\
\text { Yes } \\
\text { No }\end{array}$ & $\begin{array}{c}309 \\
34\end{array}$ & $\begin{array}{c}90.1 \\
9.9\end{array}$ \\
\hline $\begin{array}{l}\text { Initiated breastfeeding within an hour after birth } \\
\text { Yes } \\
\text { No }\end{array}$ & $\begin{array}{c}n=309 \\
259 \\
50\end{array}$ & $\begin{array}{l}83.8 \\
16.2 \\
\end{array}$ \\
\hline $\begin{array}{l}\text { Exclusively breastfed baby for } 6 \text { months } \\
\text { Yes } \\
\text { No }\end{array}$ & $\begin{array}{c}232 \\
77\end{array}$ & $\begin{array}{l}75.1 \\
24.9\end{array}$ \\
\hline $\begin{array}{l}\text { Breastfeeding pattern opted for } \\
\text { Supplemental feeding (introduction of water/formula) } \\
\text { Predominant feeding (breast milk is the predominant diet, no formula) } \\
\text { Any breastfeeding (introduction of water, infant formula, any other liquids) }\end{array}$ & $\begin{array}{c}\mathrm{n}=77 \\
30 \\
33 \\
14\end{array}$ & $\begin{array}{l}25.9 \\
62.9 \\
8.6\end{array}$ \\
\hline $\begin{array}{l}\text { Time breastfeeding was stopped } \\
\text { No breastfeeding at all } \\
\text { At } 6 \text { months } \\
\text { Between } 6 \text { and } 12 \text { months } \\
\text { Between } 12 \text { and } 18 \text { months } \\
\text { Between } 18 \text { and } 24 \text { months } \\
\text { After } 24 \text { months }\end{array}$ & $\begin{array}{c}34 \\
33 \\
131 \\
118 \\
21 \\
6\end{array}$ & $\begin{array}{c}9.9 \\
9.6 \\
38.2 \\
34.4 \\
6.1 \\
1.7\end{array}$ \\
\hline $\begin{array}{l}\text { Timing of breastfeeding } \\
\text { Hourly } \\
\text { On demand }\end{array}$ & $\begin{array}{c}n=309 \\
43 \\
266\end{array}$ & $\begin{array}{l}13.9 \\
86.1\end{array}$ \\
\hline $\begin{array}{l}\text { Duration of breastfeeding } \\
\text { Until baby is satisfied } \\
5-20 \text { minutes } \\
>20 \text { minutes }\end{array}$ & $\begin{array}{c}n=309 \\
240 \\
47 \\
22\end{array}$ & $\begin{array}{l}77.7 \\
15.2 \\
7.1\end{array}$ \\
\hline $\begin{array}{l}\text { Recommendation of exclusive breastfeeding to others } \\
\text { Yes } \\
\text { No }\end{array}$ & $\begin{array}{c}306 \\
37\end{array}$ & $\begin{array}{l}89.2 \\
10.8\end{array}$ \\
\hline
\end{tabular}


acquire adequate knowledge on breastfeeding from trained health workers. However, this finding is higher than $31 \%$ recorded in Sokoto, Nigeria. ${ }^{18}$ Higher levels of knowledge have been reported among attendant mothers in other Nigerian studies; FCT Abuja $(65 \%),{ }^{13}$ Osun, South-west $(71.3 \%)^{19}$ and Nnewi, South-east $(82 \%) .{ }^{17}$ These higher levels of knowledge reported in these studies could be related to their sources of information and the quality of baby-friendly services traditionally available at their respective health facilities. Additionally, the higher level of knowledge reported in a previous study ${ }^{13}$ within the same study area could be attributed to the study population who were working mothers with supposedly higher level of education than those in the present study. Across different African countries, findings from a study in Uganda and a systematic review of sixteen East African countries reveal the prevalence of $62.6 \%$ and range of 41.4 to $97.5 \%$ in these

Table 4. Main reason for not practising EBF.

\begin{tabular}{lcc} 
Variables & $\begin{array}{c}\text { Frequency } \\
\mathbf{N}=111\end{array}$ & $\begin{array}{c}\text { Percentage } \\
(\%)\end{array}$ \\
Breast milk insufficiency & 43 & 38.7 \\
Resumption of work & 22 & 19.8 \\
\hline Baby needs water also & 12 & 10.8 \\
Baby was too demanding & 10 & 9.0 \\
\hline Unwillingness of the child to suckle & 8 & 7.2 \\
Mother's preference & 7 & 6.3 \\
\hline Nursing makes breasts feel less sexual & 6 & 5.4 \\
Medical complications & 2 & 1.8 \\
\hline Don't think it is necessary & 1 & 0.9 \\
\hline
\end{tabular}

regions respectively. ${ }^{16,20}$ Breastfeeding practices in this study were analyzed using different variables based on WHO recommendations. Among the recommendations is initiation of breastfeeding within an hour after birth. Initiation of breastfeeding in the first hour of a baby's life establishes an emotional bond between mother and baby. ${ }^{15}$ This practice is important for child growth and development as delays in early initiation to breastfeeding has been linked to neonatal mortality. ${ }^{15}$ Out of the 309 mothers that breastfed their babies, $83.8 \%$ initiated breastfeeding within an hour after birth. This value is higher than $19.2 \%$ of children breastfed within one hour of birth based on the Nigerian 2018 National Nutrition and Health Survey (NNHS) prevalence but lies within the range of $17.7 \%$ to $98.4 \%$ (average $57.6 \%$ ) based on WHO Global Survey on Maternal and Perinatal Health. ${ }^{10,21}$ Contrary to this finding, a lower proportion of Nigerian mothers initiated breastfeeding immediately after birth in Sokoto $(53 \%),{ }^{18}$ Osun $(45 \%)^{22}$ and Katsina $(38 \%){ }^{23}$ In some parts of the country, there are beliefs that the first milk from the breast (colostrum) is harmful hence they delay early breastfeeding initiation, awaiting the flow of the unspoilt pure milk. ${ }^{18,24}$ In other African countries, initiation within one hour after delivery was reported by $39.4 \%$ mothers in Ghana, ${ }^{25}$ $68.6 \%$ in Uganda, ${ }^{20} 72.9 \%$ of the mothers in East Africa ${ }^{16}$ and $76.9 \%$ in Malawi. ${ }^{26}$ This variation could still be related to the varying level of maternal literacy and cultural practices obtainable across these African countries.

Exclusive breastfeeding in this study was practised by twothirds $(75.1 \%)$ of the mothers in this study. This result is higher than report of the WHO global survey (57.6\%), though below the $90 \%$ recommended by WHO. ${ }^{15,21}$ Across the zones in Nigeria, though the practise of breastfeeding is preserved in their culture, the prevalence of EBF for the recommended six months duration

Table 5. Factors associated with knowledge of breastfeeding among mothers in Abuja.

\begin{tabular}{|c|c|c|c|c|}
\hline Variable & $\begin{array}{c}\text { Good } \\
N=146\end{array}$ & $\begin{array}{c}\text { Poor } \\
\mathrm{N}=197\end{array}$ & $\chi^{2}$ & p-value \\
\hline $\begin{array}{l}\text { Age Categorised } \\
\leq 30 \text { years } \\
>30 \text { years }\end{array}$ & $\begin{array}{l}70(47.9) \\
76(52.1)\end{array}$ & $\begin{array}{c}97(49.2) \\
100(50.8)\end{array}$ & 0.056 & 0.813 \\
\hline $\begin{array}{l}\text { Marital status } \\
\text { Single } \\
\text { Married }\end{array}$ & $\begin{array}{c}3(2.1) \\
143(97.9)\end{array}$ & $\begin{array}{c}11(5.6) \\
186(94.4)\end{array}$ & 2.667 & 0.102 \\
\hline $\begin{array}{l}\text { Tribe } \\
\text { Igbo } \\
\text { Yoruba } \\
\text { Hausa } \\
\text { Others }\end{array}$ & $\begin{array}{l}57(39.0) \\
19(13.0) \\
25(17.1)) \\
45(30.8)\end{array}$ & $\begin{array}{c}78(39.6) \\
32(16.2) \\
19(9.6) \\
68(34.5)\end{array}$ & 4.599 & 0.204 \\
\hline $\begin{array}{l}\text { Educational Qualification } \\
\text { Informal education } \\
\text { Primary } \\
\text { Secondary } \\
\text { Tertiary } \\
\text { Qur'anic }\end{array}$ & $\begin{array}{c}0(0.0) \\
5(3.4) \\
3(2.1) \\
137(93.8) \\
1(0.7)\end{array}$ & $\begin{array}{c}1(0.5) \\
14(7.1) \\
12(6.1) \\
168(85.3) \\
2(1.0)\end{array}$ & 6.713 & 0.152 \\
\hline $\begin{array}{l}\text { Employment status } \\
\text { Employed } \\
\text { Unemployed }\end{array}$ & $\begin{array}{l}123(84.2) \\
23(15.8)\end{array}$ & $\begin{array}{c}155(78.7) \\
42(21.3)\end{array}$ & 1.692 & 0.193 \\
\hline $\begin{array}{c}\text { Number of Children Categorized } \\
1 \\
1\end{array}$ & $\begin{array}{l}57(39.0) \\
89(61.0)\end{array}$ & $\begin{array}{c}106(53.8) \\
91(46.2)\end{array}$ & 7.331 & 0.007 \\
\hline $\begin{array}{c}\text { Age of last child } \\
\leq 1 \text { year } \\
>1 \text { year }\end{array}$ & $\begin{array}{c}100(68.5) \\
46(31.5)\end{array}$ & $\begin{array}{l}126(64.0) \\
71(36.0)\end{array}$ & 0.767 & 0.381 \\
\hline
\end{tabular}


varies; in Lagos $(3.6 \%)^{27}$ and Osun $(19 \%)^{22}$ states in the Southwest, Enugu $(26 \%)^{28}$ in the South-east, Katsina $(6.7 \%)^{23}$ and Sokoto $(31 \%)^{18}$ in the North. This is an indication that the majority of mothers introduce complementary foods too early which are often of poor nutritional value to their infants. ${ }^{6}$ This variation in the prevalence of EBF remains a major concern and could be attributed to socio-cultural and religious practises/beliefs associated with child birth, feeding and nurturing practices among the various ethnic groups in Nigeria. In a Ghanaian study having a population of predominantly working mothers; it is not surprising that only $27.7 \%$ reported having exclusively breastfed their babies for the first 6 months. ${ }^{25}$ The majority of mothers here had to discontinue breastfeeding on resumption of work. In other African countries such as Uganda and Malawi, less than 50 percent (42.1\%) and $61.2 \%$ of mothers practised EBF respectively. ${ }^{20,26}$ Across different countries in East Africa, the prevalence of EBF was recorded as $55.9 \% .{ }^{16}$ This low level of practice of WHO recommended EBF pattern among mothers in Africa is not unconnected to the gap in level of knowledge on breastfeeding recorded in that region as mothers had poor knowledge on duration of breastfeeding, breastfeeding on demand and benefits of colostrum.

On bivariate analysis, number of children was associated with the level of breastfeeding knowledge in this study. Mothers with more than one child had better knowledge on breastfeeding than those with a child. This is expected as experience advances knowledge. Their years of experience usually would give them better insight into their babies' demands and possible ways to improve their welfare. Similar findings have been reported in other African countries such as Malawi and Ethiopia where secundipara women having gained experience from previous pregnancies, have better knowledge on initiation of breastfeeding. ${ }^{26,29}$ It is however, surprising that mothers who have poor knowledge had better breastfeeding practise than those with good knowledge in this study. This goes a long way in confirming the general perception that good knowledge does not always translate to good practice. A similar finding was reported in a previous study in AMAC Abuja, as knowledge of EBF in this study did not correlate with its practise; the fact that $65 \%$ of the respondents were informed of EBF did not guarantee their practicing it. ${ }^{13}$ This could be attributed to the fact that Abuja, being the FCT has a lot of women in the civil service, who though knowledgeable, might not be disposed (due to tight work schedule) to practice optimal breastfeeding as recommended by WHO. Working mothers such as civil servants have shown over the years their inability to practise EBF in a previous study in the study area. ${ }^{13}$ This was corroborated by $19.8 \%$ of the mothers who claimed the reason for nonpractice of EBF was because of their jobs. Maternity leave in Nigeria does not exceed four months hence the mothers need to return back to work after this leave or risk losing their jobs. Though the National breastfeeding policy advocates that public and private places of employment provide crèches and establish flexible nursing periods during the working hours, this is yet to be accomplished. ${ }^{6}$ Again, the belief by $38.7 \%$ of mothers in this study that breast milk is insufficient alone for babies less than six months has been a recurring challenge reported in previous studies. ${ }^{22,24,28}$ This, among other reasons is a myth that could have a socio-cultural undertone hence the need for continuous and intensified health education and promotion activities in this area. Contrary to this finding, mothers in a Ghanaian study that had adequate knowledge about EBF adopted the

Table 6. Factors associated with exclusive breastfeeding practise among mothers in Abuja.

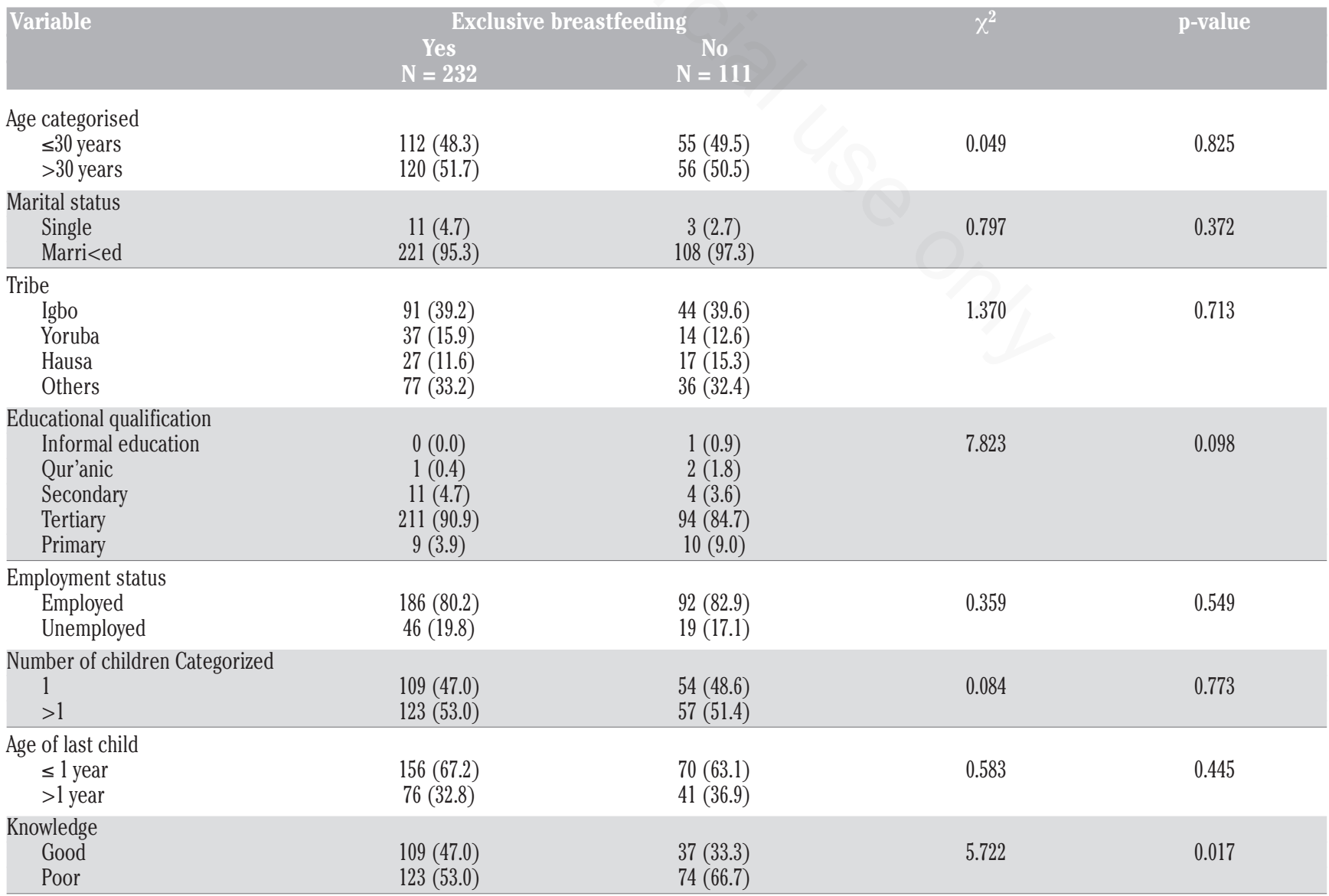


practice. ${ }^{25}$ This positive correlation could be linked to the high level of understanding of the importance of breastfeeding among participants in the study.

\section{Conclusions}

Among mothers in this study, the overall knowledge of breastfeeding was poor. Initiation of breastfeeding immediately after birth and the practice of EBF are both in line with WHO recommendations. The belief that human milk is not sufficient food for infants in the first six months of life and pressure to resume work were major challenges of EBF in this study. To sustain WHO recommended EBF practises, health education during antenatal/postnatal clinics should be intensified.

This is the first study in Abuja Nigeria, comparing the variables with WHO recommendations. However, the study is subject to some limitations. The measurement of knowledge and practise of breastfeeding could only be acquired from the questions regarding a 24 hour-recall knowledge of breastfeeding and practise, thus recall bias and social desirability bias are likely occurrence.

\section{References}

1. Ballard O, Morrow AL. Human Milk Composition: Nutrients and Bioactive Factors. Pediatr Clin North Am 2013;60:49-74.

2. Adewuyi E, Adefemi K. Breastfeeding in Nigeria: a systematic review. Int J Community Med Public Heal 2016;3:385-96.

3. United Nations Children Fund (UNICEF). Breastfeeding. A Mother's Gift, for Every Child. 2018. Accessed on 15/10/2020. Available from: https:/www.unicef.org/publications/files/ UNICEF_Breastfeeding_A_Mothers_Gift_for_Every_Child.pdf

4. Kramer MS, Kakuma R. The Optimal Duration of Exclusive Breastfeeding: a Systematic Review. World Heal Organ. 2002. Available from: https://www.who.int/nutrition/publications/optimal_duration_of_exc_bfeeding_review_eng.pdf

5. World Health Organization (WHO). Infant and young child feeding: Model Chapter for textbooks for medical students and allied health professionals. 2009. Accessed on: 15/07/20. Available from: https://apps.who.int/iris/bitstream/handle/ 10665/44117/9789241597494_eng.pdf?ua=1

6. National Policy on Infant and Young Child Feeding in Nigeria. Federal Ministry of Health, Nutrition Division ABUJA. 2005.

7. World Health Organization (WHO). Community-based strategies for breastfeeding promotion and support in developing countries. 2003;570:40. Accessed on 17/5/2020. Available from: http://apps.who.int/iris/bitstream/10665/42859/1/ 9241591218.pdf

8. Cai X, Wardlaw T, Brown DW. Global trends in exclusive breastfeeding. Int Breastfeed J 2012;7:12.

9. Issaka AI, Agho KE, Renzaho AMN. Prevalence of key breastfeeding indicators in 29 sub-Saharan African countries: A metaanalysis of demographic and health surveys (2010-2015). BMJ Open 2017;7:e014145.

10. National Bureau of Statistics (NBS) and United Nations Children's Fund (UNICEF). 2018 National Nutrition and Health Survey, Report. Abuja, Nigeria. NBS and UNICEF.

11. Agho KE, Ezeh OK, Ghimire PR, et al. Exclusive Breastfeeding Rates and Associated Factors in 13 "Economic Community of West African States" (ECOWAS) Countries. Nutrients 2019;11:3007.

12. Odu S, Deji SA, Amu E, Aduayi V. Knowledge, Attitude and
Practice of Exclusive Breastfeeding Among Mothers Attending an Infant Welfare Clinic in Osogbo, Osun State, Nigeria. Eur J Prev Med 2016;4:39-43.

13. Udoudo IOA, Ajayi PH. Working Mother Attitude and Practices of Exclusive Breastfeeding in Amac, Fct-Abuja. Int J Res Sociol Anthropol 2015;1:28-36.

14. Federal Ministry of Health. Nigeria Health Facility Registry. Accessed on 11/9/2020. Available from: https://hfr.health.gov. ng/facilities/hospitals-list

15. World Health Organization (WHO). Infant and young child feeding. A tool for assessing national practices, policies and programmes. Geneva. 2003. Accessed on 15/10/2020. Available from: https://apps.who.int/iris/bitstream/handle/ 10665/42794/9241562544.pdf

16. Dukuzumuremyi JPC, Acheampong K, Abesig J, Luo J. Knowledge, attitude, and practice of exclusive breastfeeding among mothers in East Africa: a systematic review. Int Breastfeed J 2020;15:70.

17. Onah S, Osuorah DIC, Ebenebe J, et al. Infant feeding practices and maternal socio-demographic factors that influence practice of exclusive breastfeeding among mothers in Nnewi South-East Nigeria : a cross-sectional and analytical study. Int Breastfeed J 2014;9:6.

18. Oche MO, Umar AS, Ahmed H. Knowledge and practice of exclusive breastfeeding in Kware, Nigeria. Afr Health Sci 2011;11:518-23.

19. Mbada CE, Olowookere AE, Faronbi JO, et al. Knowledge, attitude and techniques of breastfeeding among Nigerian mothers from a semi-urban community. BMC Res Notes 2013;6:552.

20. Adrawa AP, Opi D, Candia E, et al. Assessment of the Knowledge and Practices of Exclusive Breastfeeding amongst the Breastfeeding Mothers in Adjumani District, West Nile. East Afr Med J 2016;93:576-81.

21. Takahashi K, Ganchimeg T, Ota E, et al. Prevalence of early initiation of breastfeeding and determinants of delayed initiation of breastfeeding: secondary analysis of the WHO global survey. Sci Rep 2017;7:44868.

22. Agunbiade OM, Ogunleye OV. Constraints to exclusive breastfeeding practice among breastfeeding mothers in Southwest Nigeria: implications for scaling up. Int Breastfeed J 2012;7:5.

23. National Bureau of Statistics (NBS) and United Nations Children's Fund (UNICEF). Multiple indicator cluster survey 2016-17, Survey Findings Report. Abuja: National Bureau of Statistics and United Nations Children's Fund; 2017.

24. Joseph FI, Earland J. A qualitative exploration of the sociocultural determinants of exclusive breastfeeding practices among rural mothers, North West Nigeria. Int Breastfeed J 2019;14:38.

25. Nukpezah RN, Nuvor SV, Ninnoni J. Knowledge and practice of exclusive breastfeeding among mothers in the tamale metropolis of Ghana. Reprod Health 2018;15:140.

26. Nkoka O, Ntenda PAM, Kanje V, et al. Determinants of timely initiation of breast milk and exclusive breastfeeding in Malawi: a population-based cross-sectional study. Int Breastfeed J 2019;14:37.

27. Akodu SO, Njokanma OF, Kehinde OA. Exclusive breastfeeding practices among women attending a private health facility in Lagos, Nigeria. Niger J Paed 2014;41:345-9.

28. Bisi-onyemaechi AI, Chikani UN, Ubesie AC, et al. Factors associated with low rate of exclusive breastfeeding among mothers in Enugu, Nigeria. Int J Res Med Sci 2017;5:3776.

29. Liben ML, Yesuf EM. Determinants of early initiation of breastfeeding in Amibara district, Northeastern Ethiopia: a community based cross-sectional study. Int Breastfeed J 2016;11:7. 